\title{
104. On L-Thebainol ${ }^{1)}$
}

\author{
By Kakuji Goтo, м.J.A., and Izuru Yамамото \\ Department of Chemistry, Kitasato Institute, Tokyo, Japan \\ (Comm. Oct. 12, 1953)
}

In the previous paper ${ }^{2)}$, we reported the preparation of 7demethoxysinomeninol (I) and its laevorotation. As the skeleton of thebaine is the optical antipode of that of sinomenine, we expected that the thebainol from thebaine must be dextrorotatory. It is now found that this is actually the case and the latter well racemizes with the former.

Thebainol from thebaine is one of rare cases of dextrorotation in morphine group, where the morphinane skeleton is kept intact ${ }^{33}$. But from this discovery, the nomenclature in sinomenine and morphine groups suffers some confusion. If we name 7-demethoxysinomeninol (I), for convenience sake, simply, (-)-thebainol, then the reader may acquire the impression as if it is originated from thebaine and not from sinomenine. The same is true of thebenone (II) and its intermediates. Thebenone from thebaine (-) is dextrorotatory and from sinomenine $(-)$ is laevorotatory. Moreover, the direction of rotation inverts at every stage from dihydrothebainone to thebenone as we showed long $\mathrm{ag}^{4}{ }^{4}$.

From thebaine

1) Dihydrothebainone $-59^{\circ}$

2) des-N-methyl-dihydrothebainone $+55^{\circ}$

3) Dihydro-des-N-methyldihydrothebainone $-68^{\circ}$

4) Thebenone (II) $+79^{\circ}$

5) Dehydro-thebenone (III) + $207^{\circ}$
From sinomenine

1) Demethoxydihydrosinomenine $+59^{\circ}$

2) des-N-methyl-demethoxydihydrosinomenine $-55^{\circ}$

3) Dihydro-des-N-methyldemethoxydihydrosinomenine $+68^{3}$

4) Thebenone $-79^{3}$

5) Dehydro-thebenone $-207^{\circ}$

We propose, therefore, after the example of amino acids and monosaccharides, to prefix $\mathrm{L}$ to the names of the derivatives from thebaine and $\mathrm{D}$ to the names from sinomenine, although the absolute stereochemical configuration of morphine is not yet ascertained ${ }^{5)}$. In the above list, for example, we wish to name the derivatives from sinomenine directly after the name of corresponding substances from thebaine, only prefixing with $D$.

It may be limited to necessary cases. The names (-)-and 
(+)-dihydromorphine ${ }^{6}$, show naturally their origin and accordingly the $\mathrm{L}$ and $\mathrm{D}$ are quite superfluous. But, D-thebainol-(-) will clearly indicate that this substance is derived from sinomenine and is laevorotatory. The similar explanation will be given of $\mathrm{L}^{-}$ thebenone- $(+)$ and $D$-thebenone- $(-)$.

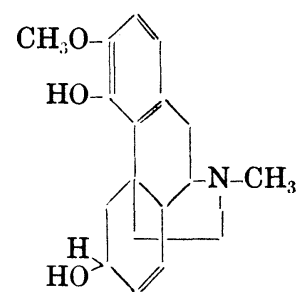

I. Thebainol

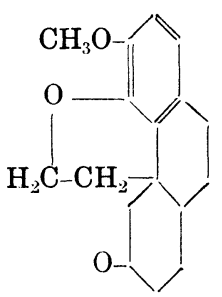

II. Thebenone

III. Dehydrothebenone $(9,10-\mathrm{CH}=\mathrm{CH}-)$

We hope that our proposition will be taken into consideration by chemical circles. Nevertheless, we will use this nomenclature tentatively in our papers to prove or disprove the utility of this proposition.

\section{Experimental}

L-Thebainol- $(+)(\mathrm{I})$

L-Thebainone (0.9 gr.) was reduced by boiling with $\mathrm{LiAlH}_{4}$ $(0.4 \mathrm{gr}$.$) in tetrahydrofurane (25 \mathrm{cc}$.) for two hours. The reduced base was taken up in chloroform and the chloroform residue was twice recrystallized from acetone. Short prisms. M.p. $181^{\circ}$. $[\alpha]_{D}^{26}=+94.5^{\circ}$ (c 1.937, chlf.) ${ }^{7}$. (Anal. Calcd. for $\mathrm{C}_{18} \mathrm{H}_{23} \mathrm{O}_{3} \mathrm{~N}(301.4)$ : $\mathrm{C}$, 71.73; H, 7.69; N, 4.65. Found : C, $71.96 ; \mathrm{H}, 7.54 ; \mathrm{N}, 4.81$. )

Diacetyl-derivative. Prepared by warming the substance with acetic anhydride and fused sodium acetate on water bath for three hours. Prisms from acetone. M.p. 173'. Yield good. (Anal. Calcd. for $\mathrm{C}_{22} \mathrm{H}_{27} \mathrm{O}_{5} \mathrm{~N}(385.44)$ : C, 68.55; H, 7.06; N, 3.63. Found : C, 68.28; $\mathrm{H}, 7.02$; N, 3.66.)

$$
d \text {, l-Thebainol }
$$

$83 \mathrm{mgr}$. each of L-and $\mathrm{D}$-thebainol was dissolved in methanol and brought into crystallization by evaporation. Long prisms. M.p. $193^{\prime}$ (from methanol or acetone). $\alpha= \pm 0$ s

We thank Prof. Eiji Ochiai for his kind interest shown in this proposition and Sankyo Pharmaceutical Company for the microanalysis. The cost of this investigation was partly defrayed by a grant from the Ministry of Education.

\section{References}

1) The 64 th Comm. on Sinomenine.

2) K. Goto and I. Yamamoto: Proc. Japan Acad., 29, 210 (1953).

3) Compare, for example, Manske and Holmes: The Alkaloids, 2, 124-152, 208-216. 
4) K. Goto, R. Inaba, and H. Shishid): Ann., 485, 247 (1931); K. Goto, H. Michinaka, and H. Shishido: Ann., 515, 302 (1935).

5) See, however, Bijvoet et al.: Nature, 168, 271 (1951) and Bick: Nature, 169, 755 (1952).

6) K. Goto and T. Arai : Ann., 547, 194 (1941).

7) We reexamined the rotation of D-thebainol (former value $[\alpha]_{\mathrm{D}}^{6}=-90.3^{\circ}$ ) and obtained the value corresponded to that of L-thebainol, namely $[\alpha]_{\mathrm{D}}^{20}=-94.8^{\circ}$ (c 0.707 , chlf.). 